\title{
New QSAR and Solvatochromic Estimation of Molecular Parameters of Chlortetracycline
}

\author{
ANTONINA GRITCO-TODIRASCU ${ }^{1}$, DORINA EMILIA CREANGA ${ }^{1}$, LILIANA MIHAELA IVAN ${ }^{1 *}$, \\ DANA ORTANSA DOROHOI ${ }^{1}$, ANAMARIA CIUBARA ${ }^{2}$ \\ ${ }^{1}$ Alexandru Ioan Cuza University of Iasi, Faculty of Physics, 11 Carol I Blvd., Iasi, Romania \\ ${ }^{2}$ Dunarea de Jos, University of Galati, Faculty of Medicine and Pharmacy, 35 Alexandru Ioan Cuza Str., Galati, Romania
}

The present paper is focused on determination of the main parameters of Chlortetracycline. Chlortetracycline belongs to one of the most used family of antibiotics worldwide, Tetracyclines. Because of the large spectrum of infections which can be treated with this category of antibiotics there are attempts to find new derivatives from this class. The compounds derived from the same basic structure exhibit same chemical properties, that is why knowing in detail the main physico-chemical properties of Chlortetracycline could be a real help in synthesize new efficient derivatives. In order to evaluate the reactivity and biological activity HyperChem was used to establish the optimized structure, the electro-optical, the energetic and QSAR parameters. The solvatochromic methods allowed determining the intermolecular interactions types and their contribution to the spectral shifts of measured electronic absorption bands. Based on computational and solvatochromic results, the excited state dipole moment of Chlortetracycline was established by variation method.

Keywords: chlortetracycline, QSAR, solvatochromism, excited dipole moment

Chlortetracycline (4S,4aS,5aS,6S,12aR)-7-chloro-4-(dimethylamino) - 1,6,10,11,12a - pentahydroxy - 6 - methyl - 3,12 - dioxo - 4, 4a, 5, 5a - tetrahydrotetracene - 2 - carboxamide $-\mathrm{C}_{22} \mathrm{H}_{23} \mathrm{ClN}_{2} \mathrm{O}_{8}$ ) [1], is a broad spectrum antibiotic with antibacterial action in the case of many Gram-positive and Gram-negative bacteria.

The name "tetracycline" comes from the structure with four rings, all tetracyclines being considered derivatives of polycyclic naphthacene carboxamide. Chlortetracycline (CTC) was discovered by Benjamin Duggar [2]. It resulted as a product of natural fermentation of Streptomyces aureofaciens and received the name Aureomycin (due to its golden colour) [3].

Clinical tests emphasized a low toxicity and a large area of therapeutic applications of tetracyclines in human and veterinary use [4].

The computational and solvatochromic studies of CTC will provide some energetic and microscopic parameters of this antibiotic and its interactions with different solvents.

The information about the excited state dipole moment from this paper can help researchers in obtaining quantum mechanical models for the excited states of CTC and its derivatives.

\section{Computational and experimental details}

CTC crystallized powder and pure solvents from Merck were used without further purification.

Computational study was made with HyperChem 8 [5] using PM3 method, which is, statistically proven, more accurate than the other semiempirical methods, in determining the main parameters of small molecules [6]. The optimized structure of CTC was obtained with Polak-Ribiere algorithm (RMS gradient $=0.0001 \mathrm{kcal} /$ Åmol, 500 maximum cycles).

The electronic absorption spectra (EAS) were recorded at UV-Vis Spectrophotometer Shimadzu UV-1700. CTC crystallized powder and pure solvents from Merck were used without further purification. The limited solubility of CTC determined the reduced number of solvents in which EAS were recorded. Binary and ternary solutions were obtained dissolving small amounts $\left(\mathrm{c}=10^{-4} \mathrm{~mol} / \mathrm{L}\right)$ of spectrally active molecule in pure solvents and in $\mathrm{n}$ propanol/water mixtures (in different volumetric ratios).

\section{Results and discussions}

a.Computational

Optimized structure of CTC is presented in figure 1.

*email: mihaelaivan2002@yahoo.com 


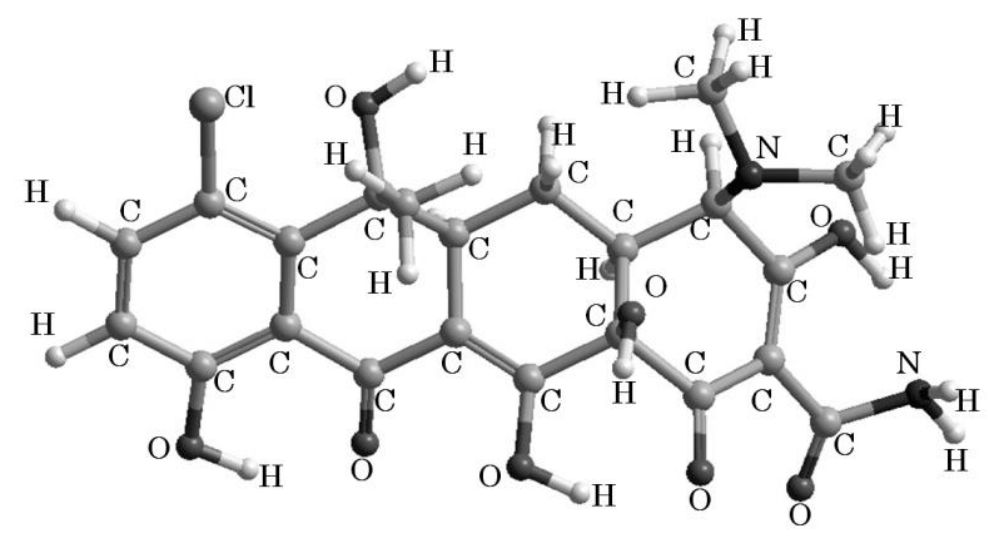

Fig. 1 Structural formula of CTC

In order to correlate the biological activity with the structure of a given molecular system, the quantitative structure - activity relation analysis (QSAR) was used [7]. This consists in finding an equation between some physico-chemical and structural parameters of the studied molecule, called descriptors: the frontier orbitals, molecular weight, chemical potential etc. These descriptors are used further, to calculate other quantities, like half maximal inhibitory concentration having an important role in prediction toxicity of a drug [8].

HOMO/LUMO (Highest Occupied Molecular Orbital/Lowest Unoccupied Molecular Orbital) energies are very important notions in chemistry [9].

In his article, Koopmans [10] considered that the ionization potential (IP) of molecules could be approximate by the value of $-\mathrm{E}_{\text {Hомо }}$ and the electron affinity (EA) by $-\mathrm{E}_{\mathrm{LUMO}}$.

Taking into account this, we can write:

$$
\begin{aligned}
& I P \approx-E_{\text {НОМО }} \\
& E A \approx-E_{L U M O}
\end{aligned}
$$

The values for the frontier orbital energies could be used to calculate other important parameters like chemical potential, chemical hardness and electrophilicity index, related with the chemical reactivity and biological activity of the studied compound.

Chemical potential $(\mu)[11]$ is defined as the energy that can be absorbed or released during a chemical reaction (or phase transition) due to the change of the particle number in the studied system.

Using the values for HOMO and LUMO energies, the chemical potential can be approximate using the following relation:

$$
\mu=\frac{E_{\text {HOMO }}+E_{\text {LUMO }}}{2}=-\frac{1}{2}(I P+E A)
$$

Chemical hardness $(\eta)$ is a concept which helps to understand reactivity based on the quantum chemistry notions [12].

$$
\eta=\frac{E_{\text {LUMO }}-E_{\text {HOMO }}}{2}=\frac{1}{2}(I P-E A)
$$

Global electrophilicity index $(\omega)[13,14]$ was introduced to measure the stabilization in energy when the system acquires an additional electronic charge from the environment The local extension of this index provides useful information about the active sites of electrophiles, allowing us to characterize the intramolecular selectivity in the studied systems. Ingold $[15,16]$ introduced the concepts of electrophile and nucleophile for atoms and molecules, associated with electron-deficient and electron-rich species, respectively.

The electrophilicity concept has been connected to global reactivity indexes defined for the ground states of atoms and molecules [17].

The global electrophilicity index can be calculated using relation (5):

$$
\omega=\frac{\mu^{2}}{2 \eta}
$$

The following values were obtained in the case of CTC: $\mu=4.945 \mathrm{eV}, \eta=3.825 \mathrm{eV}$ and $\omega=3.196 \mathrm{eV}$.

Other important parameter computed by QSAR option in HyperChem, is $\log P$ [18] - partition coefficient noctanol/water - which shows us if one compound is lipophilic or hydrophilic. 
Table 1

QSAR AND ENERGETIC PARAMETERS OF CTC

\begin{tabular}{|cccc|}
\hline QSAR parameters & \multicolumn{3}{c|}{ Energetic parameters } \\
\hline Surface area $\left(\AA^{2}\right)$ & 609.96 & Total energy $(\mathrm{kcal} / \mathrm{mol})$ & -137247 \\
Volume $\left(\AA^{3}\right)$ & 1109.43 & Heat of formation $(\mathrm{kcal} / \mathrm{mol})$ & -273 \\
Hydration energy $(\mathrm{kcal} / \mathrm{mol})$ & -20.90 & Binding energy $(\mathrm{kcal} / \mathrm{mol})$ & -5963 \\
$\log \mathrm{P}$ & -3.31 & $\mathrm{IP}(\mathrm{eV})$ & 8.77 \\
Refractivity $\left(\AA^{3}\right)$ & 121.24 & $\mathrm{EA}(\mathrm{eV})$ & 1.12 \\
Polarizability $\left(\AA^{3}\right)$ & 45.16 & Dipole moment $p(\mathrm{D})$ & 6.89 \\
\hline
\end{tabular}

The planar distribution of the four cycles in the optimized structure of CTC demonstrates the existence of a large $\pi$ conjugation and a high molecular polarizability value (see Table 1).

Molecule's radius can be calculated using the relation [19]:

$$
r=\frac{3 V}{A}
$$

$\mathrm{V}$ is the volume and A is the surface area of CTC given by HyperChem and listed in Table 1.

\section{b. Spectral}

The electronic absorption spectra were recorded in 11 pure and in 8 binary solvents obtained by mixing n-propanol with water.

The solvent parameters were taken from literature [20-22] and listed in Table 2 along with wavenumbers in the visible $\pi-\pi^{*}$ band of CTC.

In a previous paper, the solvent shift was expressed by a multilinear regression in which only universal interactions are considered [23].

Considering the CTC structure, some hydrogen bonds by accepting or donating protons, certainly act in CTC solutions with hydroxyl solvents. For this reason we consider to complete our previous research by adding supplementary terms for specific interactions.

The wavenumber in the maximum of the electronic absorption bands (both in UV and in visible ranges) can be correlated with the solvent parameters by using an equation of the type (7):

$$
v=v_{0}+C_{1} f(\varepsilon)+C_{2} f(n)+C_{3} \beta+C_{4} \alpha
$$

In (7), $v_{0}$ signifies the frequency of the isolated molecule; $C_{l}$ and $\mathrm{C}_{2}$ are coefficients, depending on the microscopic parameters of solute molecule, indicate the presence of universal interactions in solutions, while $C_{3}$ and $C_{4}$ describe its specific interactions with the solvent molecules.

The statistical analysis of equation (7), with ORIGIN [26], based on the data from Table 2 gives equation (8):

$$
v=26796.9+1332.7 f(\varepsilon)-4235.9 f(n)-89.4 \beta-217.5 \alpha
$$

According to the solvatochromic theories, a multiple linear regression of the type (7) can be used in the analyze of the spectral data as function on the orientation - induction and dispersive - polarization interactions described by the terms $\mathrm{C}_{1} f(\varepsilon)$ and $\mathrm{C}_{2} f(n)$; where $f(\varepsilon)=\frac{\varepsilon-1}{\varepsilon+2}$ and $f(n)=\frac{n^{2}-1}{n^{2}+2}$ and on specific interactions with donating and receiving protons by spectrally active molecule, described by the terms $C_{3} \beta$ and $C_{4} \alpha[22,27]$, respectively.

\begin{tabular}{|c|c|c|c|c|c|c|}
\hline No. & Solvent & $v_{\exp \left(\mathrm{cm}^{-1}\right)}$ & $f(\varepsilon)$ & $\mathbf{f}(\mathbf{n})$ & $\alpha$ & $\beta$ \\
\hline 1 & Acetic acid & 26392.0 & 0.635 & 0.228 & 0.45 & 1.12 \\
\hline 2 & n-Pentanol & 26605.8 & 0.809 & 0.248 & 0.86 & 0.84 \\
\hline 4 & Isobutanol & 26677.2 & 0.845 & 0.240 & 0.84 & 0.79 \\
\hline 5 & Isopropanol & 26751.0 & 0.850 & 0.231 & 0.84 & 0.76 \\
\hline 6 & n-Propanol & 26674.5 & 0.861 & 0.235 & 0.9 & 0.84 \\
\hline 8 & Methanol & 26744.6 & 0.905 & 0.203 & 0.66 & 0.98 \\
\hline 9 & Ethylene glycol & 26884.8 & 0.913 & 0.258 & 0.69 & 0 \\
\hline 10 & Water & 26614.1 & 0.916 & 0.258 & 0.52 & 0.9 \\
\hline 11 & DMF & 27012.1 & 0.947 & 0.206 & 0.47 & 1.17 \\
\hline
\end{tabular}

Table 2

WAVENUMBER IN THE MAXIMUM OF THE VISIBLE BAND OF CTC AND THE SOLVENT PARAMETERS 


\begin{tabular}{|c|c|c|c|c|c|c|}
\hline 12 & n-Propanol+0.02 water & 26674.0 & 0.864 & 0.233 & 0.83 & 0.98 \\
\hline 13 & n-Propanol+2.\% water & 26687.0 & 0.872 & 0.232 & 0.848 & 1.008 \\
\hline 14 & n-Propanol+5\% water & 26700.0 & 0.879 & 0.232 & 0.828 & 1.025 \\
\hline 15 & n-Propanol+9\% water & 26720.0 & 0.890 & 0.230 & 0.824 & 1.033 \\
\hline 16 & n-Propanol+16\% water & 26754.0 & 0.905 & 0.228 & 0.812 & 1.008 \\
\hline 17 & n-Propanol+22\% water & 26779.0 & 0.915 & 0.226 & 0.797 & 0.971 \\
\hline 18 & n-Propanol+28\% water & 26790.0 & 0.921 & 0.225 & 0.781 & 0.936 \\
\hline 19 & n-Propanol+32\% water & 26812.0 & 0.926 & 0.224 & 0.767 & 0.910 \\
\hline
\end{tabular}

The values of $\mathrm{C}_{1}-\mathrm{C}_{4}$ regression coefficients were used to estimate the contribution of each type of interactions to the spectral shifts of $\pi-\pi^{*}$ visible band of CTC in different solvents.

The supply of each type of interactions to the total spectral shift in a given solvent is listed in Table 3. In Table 3, $\mathrm{P}_{1}-\mathrm{P}_{4} \%$ are the contributions (expressed in percents) of each type of interaction to the total spectral shift. As it results from this table, the major contribution of the universal interactions (orientation-induction with $\mathrm{P}_{1} \%$ - described be the term $\left.C_{1} f(\varepsilon)\right)$ and dispersion-polarization with $\mathrm{P}_{2} \%$ - described by $\left.C_{2} f(n)\right)$ is almost $90 \%$.

Table 3

PERCENTAGE CONTRIBUTION TO THE SPECTRAL SHIFT OF VISIBLE $\pi-\pi^{*}$ ABSORPTION BAND OF CTC

\begin{tabular}{|c|c|c|c|c|c|}
\hline No. & Solvent & $\mathbf{P}_{\mathbf{1}} \%$ & $\mathbf{P}_{\mathbf{2}} \%$ & $\mathbf{P}_{\mathbf{3}} \boldsymbol{\%}$ & $\mathbf{P}_{\mathbf{4}} \%$ \\
\hline 1 & Acetic acid & 42.05 & 48.05 & 4.98 & 4.87 \\
\hline 2 & n-Pentanol & 45.11 & 43.91 & 3.15 & 7.83 \\
\hline 3 & n-Butanol & 46.69 & 42.60 & 7.83 & 7.58 \\
\hline 4 & Isobutanol & 46.98 & 42.45 & 2.95 & 7.62 \\
\hline 5 & Isopropanol & 48.00 & 41.38 & 2.88 & 7.74 \\
\hline 6 & n-Propanol & 47.55 & 41.23 & 3.11 & 8.11 \\
\hline 7 & Ethanol & 49.86 & 39.95 & 3.27 & 6.93 \\
\hline 8 & Methanol & 52.50 & 37.44 & 3.81 & 6.25 \\
\hline 9 & DMF & 49.52 & 44.38 & 0.00 & 6.10 \\
\hline 10 & Ethylene glycol & 48.70 & 43.58 & 3.21 & 4.51 \\
\hline 11 & Water & 53.92 & 37.25 & 4.47 & 4.37 \\
\hline 12 & n-Propanol+0.02\% water & 47.83 & 41.03 & 3.64 & 7.50 \\
\hline 13 & n-Propanol+2.5\% water & 48.00 & 40.66 & 3.72 & 7.62 \\
\hline 14 & n-Propanol+5\% water & 48.33 & 40.47 & 3.78 & 7.42 \\
\hline 15 & n-Propanol+9\% water & 48.75 & 40.09 & 3.79 & 7.36 \\
\hline 16 & n-Propanol+16\% water & 49.44 & 39.63 & 3.69 & 7.24 \\
\hline 17 & n-Propanol+22\% water & 60.63 & 47.72 & 4.32 & 8.62 \\
\hline 18 & n-Propanol+28\% water & 50.44 & 39.14 & 3.44 & 6.98 \\
\hline 19 & n-Propanol+32\% water & 50.42 & 38.68 & 4.09 & 6.81 \\
\hline
\end{tabular}

In protic solvents, the specific interactions of the hydrogen bond type in which the solvent accepts protons $\left(\left(C_{3} \beta\right)\right.$ having a percent $\left.\mathrm{P}_{3} \%\right)$ or donates protons $\left(C_{4} \alpha\right.$ with a percent $\left.\mathrm{P}_{4} \%\right)$ have a contribution near $10 \%$ (see Table 3 ).

\section{c) Variational method}

The statistical analysis of the solvatochromic data can also be used in order to determine the excited state dipole moment $p_{e}$ and the angle $\varphi$ between the dipole moments $p_{g}$ and $p_{e}$ in the two electronic states participating to the $\pi-\pi^{*}$ transition, by a variational method $[27,28]$.

The regression $C_{1}$ şi $C_{2}$ coefficients depend on the microscopic parameters as it results from (9) and (10)

$$
\begin{aligned}
C_{2} & =\frac{p_{g}{ }^{2}-p_{\varepsilon}{ }^{2}}{h c a^{3}}-\frac{2 p_{g}\left(p_{g}-p_{\varepsilon} \cos \varphi\right)}{h c a^{3}}-3 k T \frac{\alpha_{g}-\alpha_{\varepsilon}}{a^{3}}+\frac{3}{2} \frac{\alpha_{g}-\alpha_{\varepsilon}}{a^{3}} \frac{I(u) I(v)}{I(u)+I(v)} \\
C_{1} & =\frac{2 p_{g}\left(p_{g}-p_{\varepsilon} \cos \varphi\right)}{h c a^{3}}+3 k T \frac{\alpha_{g}-\alpha_{\varepsilon}}{a^{3}}
\end{aligned}
$$

Using relations (9) and (10), the following equations were obtained:

$$
\alpha_{e}=57,271-0,0858 p_{e}^{2}
$$

and

$$
0.0104 p_{e}^{2}-13.78 p_{e} \cos \varphi+50,4728=0
$$


When the angle $\varphi$ varies, one obtains the corresponding values for the excited state dipole moment and polarizability of the studied molecule, based on relations (11) and (12). When the angle $\varphi$ increases between $[0 ; 83]^{0}$, the excited state dipole moments increases, while the excited state polarizability decreases.

From the multitude of the obtained results, one chooses the value at which the electric polarizability becomes equal (or approximate equal) with the ground state electric polarizability [27, 28]. At $\varphi=71.50^{\circ}$ the polarizability from the excited state equalizes the ground state polarizability of CTC.

Table 4

EXCITED STATE CTC DIPOLE MOMENT AND POLARIZABILITY FOR $\pi-\pi^{*}$ TRANSITION AT DIFFERENT ANGLES $\varphi$

\begin{tabular}{|c|c|c|c|c|c|c|c|}
\hline $\boldsymbol{\varphi}\left(\mathbf{(}^{\mathbf{}}\right)$ & $\mathbf{p}_{\mathbf{e}}$ & $\boldsymbol{\alpha} \mathbf{e}$ & $\mathbf{R}_{\mathbf{1}}$ & $\boldsymbol{\varphi} \mathbf{( \mathbf { 0 }}^{\mathbf{0}}$ & $\mathbf{\mathbf { p } _ { \mathbf { e } }}$ & $\boldsymbol{\boldsymbol { \alpha } _ { \mathbf { e } }}$ & $\mathbf{R}_{\mathbf{1}}$ \\
\hline 0 & 3.67 & 56.11 & -33.45 & $\mathbf{7 1 . 5 0}$ & $\mathbf{1 1 . 8 8}$ & $\mathbf{4 5 . 1 6}$ & $-\infty$ \\
\hline 10 & 3.73 & 56.08 & -33.54 & 71.6 & 11.95 & 45.04 & 2955.04 \\
\hline 20 & 3.91 & 55.96 & -33.87 & 72 & 12.22 & 44.46 & 508.28 \\
\hline 30 & 4.24 & 55.72 & -34.67 & 73 & 12.96 & 42.86 & 152.92 \\
\hline 40 & 4.80 & 55.29 & -36.08 & 74 & 13.81 & 40.91 & 82.34 \\
\hline 50 & 5.74 & 54.45 & -39.19 & 75 & 14.79 & 38.68 & 52.23 \\
\hline 60 & 7.41 & 52.56 & -48.99 & 76 & 15.93 & 35.49 & 35.67 \\
\hline 65 & 8.81 & 50.68 & -65.17 & 77 & 17.28 & 31.94 & 25.80 \\
\hline 70 & 10.97 & 46.94 & -201.88 & 78 & 18.91 & 26.57 & 18.07 \\
\hline 71 & 11.56 & 45.81 & -558.40 & 79 & 20.93 & 19.69 & 12.92 \\
\hline 71.3 & 11.75 & 45.54 & -933.56 & 80 & 23.49 & 9.92 & 9.06 \\
\hline 71.4 & 11.81 & 45.30 & -2607.74 & 81 & 29.18 & -15.79 & 4.34 \\
\hline 71.42 & 11.83 & 45.27 & -3220.94 & 82 & 31.80 & -29.51 & 3.75 \\
\hline 71.48 & 11.87 & 45.19 & -11818.19 & 83 & 39.93 & -79.53 & 1.83 \\
\hline
\end{tabular}

Considering that the change in the values of the excited state polarizability modifies the sign of $\mathrm{C}_{1} \alpha$, the component of the regression coefficient $C_{1}$ depending on molecular polarizability, one can assume that the value $\varphi=71.5^{0}$ is the angle between the dipole moments at which the absorption process takes place (Table 4).

Let us plot the triangle of dipole moments for the absorption process corresponding to the visible band appearance.

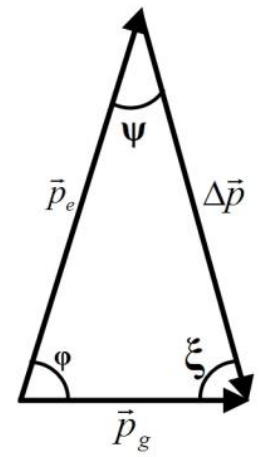

Fig. 2. Dipole moments trangle for the studied transition

The triangle can be solved by using law of sines and the value $p_{g}=6.89 \mathrm{D}$ computed by HyperChem. The angle between $p_{e}$ and $p_{g}$ can be considered $\varphi=71.5^{\circ}$. Making the calculus in this triangle, one obtains the following values:

$$
\psi=33.97^{0}, \xi=74.53^{\circ} \text { and } \Delta p=11.69 \mathrm{D} .
$$

The $\pi-\pi^{*}$ transition responsible for the visible electronic absorption band appearance takes place with significant increasing of the dipolar moment. The difference $\Delta p$ has the module comparable with the excited state dipole moment (see Table 4) and it makes an angle $\xi=74.53^{\circ}$ with the ground state dipole moment of CTC.

From relation (9) it results that the coefficient $C_{1}$ giving the contributions of the two types of universal interactions, orientation-induction and dispersion-polarization, can be separated as it follows:

$$
\begin{gathered}
C_{1, \mu}=\frac{2 p_{g}\left(p_{g}-p_{e} \cos \varphi\right)}{h c a^{3}} \\
C_{1 \alpha}=3 k T \frac{\alpha_{g}-\alpha_{e}}{a^{3}}
\end{gathered}
$$


The discontinuity of ratio $R_{1}=\frac{C_{1 \mu}}{C_{1 \alpha}}$ molecule, caused by the $\pi-\pi^{*}$ absorption.

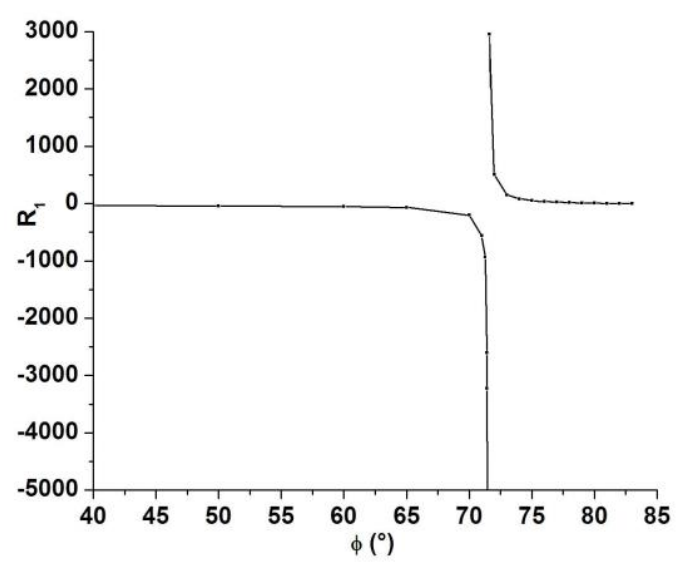

Fig. 3 Plot of R1 versus angle $\varphi$

Figure 3 emphasizes a discontinuity at the value $71.5^{\circ}$ of angle $\varphi$, where the electronic transition takes place.

In the future studies we intend to apply Abe theory [29] for determining the dipole moments of CTC in the electronic states participating in absorption process, as it applied for anthracene molecule [30, 31].

\section{Conclusions}

By using HyperChem, the most important parameters of Chlortetracycline were computed: polarizability, $\log$, hydration energy, the values of the frontier orbital energies, chemical potential, chemical hardness, electrophilicity index. Some of these parameters, called descriptors, are used to estimate half maximal inhibitory concentration having a role in prediction toxicity of a drug.

Computational and solvatochromic studies allowed us to evaluate the dipole moments of CTC in the ground and excited state of absorption process. By excitation the dipole moment of CTC increases, determining a high value of the transition dipole moment for $\pi-\pi^{*}$ visible absorption band. The contribution of various types of interactions was estimated based on multiple linear regression analysis.

\section{References}

1.***https://pubchem.ncbi.nlm.nih.gov/compound/chlortetracycline\#section=Names-and-Identifiers

2.DUGGAR, B.M., Ann N Y Acad Sci., 51(ART)M 1948, p. 177

3.GALLAGHER, J.C., MacDOUGALL, C. - Antibiotics Simplified, Jones \& Bartlett Learning, 2008, ISBN-10: 1284111296

4.CORNEJO, J., YEVENES, K., AVELLO, C., POKRANT, E., MADDALENO, A., San MARTIN, B., LAPIERRE, L., Molecules, 23, 2018, p. 1264

$5 . * * *$ www.hyperchem.com

6.STEWART, J.J.P., J Comput Chem, 10, No. 2, 1989, p. 209

7.JAIN, A. K., RAVICHANDRAN, V., SINGH, R., SHARMA, S., MOURYA, V. K., AGRAWAL, R. K., Dig J Nanomater Bios, 3, No.2, 2008, p. 63

8.HAGHDADI, M., FATEMI, M. H., Bull. Chem. Soc. Jpn, 83, No. 4, 2010, p. 345;

9.CHEPTEA, C., DULCESCU, M.M., DOROHOI, D.O., SUNEL, V., DESBRIERES, J., Dig J Nanomater Bios, 7, No 1, 2012, p. 287

10.KOOPMANS, T., Physica. Elsevier. 1, No. (1-6), 1934, p.104

11.KAPLAN, T.A., J Stat. Phys, 122, Iss.6, 2006, p. 1237

12.PEARSON, R.G. - Chemical hardness, Wiley. 2005, ISBN 9783527294824

13.MAYNARD, AT, HUANG, M, RICE, WG, COVELL DG, Proc Natl Acad Sci U S A., 95, No. 20, 1998, p. 11578

14.PARR, R. G., SZENTPÁLY, L.V., LIU, S, J., Am. Chem. Soc., 121, No. 9, 1999, p. 1922

15.INGOLD, C.K., Recl, Trav. Chim. Pays-Bas, 48, 1929, p. 797

16.INGOLD, C. K., Chem. Rev. 15, 1934, p. 225

17.ROY, R.K.; TAJIMA, N; HIRAO, K., J. Phys. Chem. A, 105, 2001, p. 2117

18.KWON, Y - Partition and Distribution Coefficients. in Handbook of Essential Pharmacokinetics, Pharmacodynamics and Drug Metabolism for Industrial Scientists. New York: Kluwer Academic/Plenum Publishers, 2001, ISBN 978-0-306-46234-4

19.MOROSANU, A.C, BENCHEA, A.C., BABUSCA, D, DIMITRIU, D.G, DOROHOI, D.O, Anal. Lett, 50, no. 17, 2017, p. 2725

20.REICHARDT, C. - Solvents and Solvent Effects in Organic Chemistry, Third Edition, Wiley - VCH Verlag GmbH \& Co. 2006, ISBN: 978-3 527-60567-5

21. BENCHEA, A.C, BABUSCA, D, DOROHOI, D.O, Spectrochim Acta Part A, 172, 2017, p. 91

22.MOROSANU, A.C., GRITCO-TODIRASCU, A., CREANGA, D.E., DOROHOI, D.O., Spectrochim Acta Part A, 189, 2018 , p. 307 
23.OANCA, G., NADEJDE, C., FIFERE, N., GRITCO TODIRASCU A., CREANGA, D., DOROHOI, D., STARE J., J Mol Struct, 1126, 2016, p. 177

24.MOROSANU, A.C, DIMITRIU D.G., DOROHOI, D.O., J Mol Struct,, 1180, 2019, p. 723

25.LUCA, A.C., MOROSANU, A.C., MACOVEI, I., DIMITRIU, D.G., DOROHOI, D.O., STRATULAT, L.S., Rev.Chim.(Bucharest), 70, no. 10,2019 , p. 3538

26.***www.originlab.com

27.DOROHOI, D.O., PARTENIE, D.H., CALUGARU, A.C., Spectrochim Acta Part A, 213, 2019, p. 184

28.DOROHOI, D.O., Ukr. J. Phys, 63, No. 8, 2018, p.701

29.McRAE, E. G., J. Phys. Chem., 61 1957, p. .562

30.KAWSKI, A., Z. Naturforsch., 57a, 2002, p. 255

31.ABE, T., Bull. Chem. Soc. Jpn, 39, 1966, p. 936; 64, No. 11, 1991, p. 3224

32.TIGOIANU, R.I., DOROHOI, D.O, AIRINEI. A, Rev. Chim., 60, no.1, 2009, p. 72

33.TIGOIANU R.I., AIRINEI, A., DOROHOI D.O., Rev. Chim., 61, no.5, 2010, p. 491

Manuscript received: 26.09 .2019 